\title{
Cultivation of Science Teachers' Information Literacy in China
}

\author{
Haibin Sun \& Tingting Liu \\ Department of Physics and Electronics, Taishan University \\ Tai'an 271021, China \\ E-mail: sunhbphy@hotmail.com
}

The research is supported by the Shandong Education Science "eleven five" Plan (2008GG179).

\begin{abstract}
In the paper, we focus on the information literacy of science teachers in China. Information literacy encompasses knowledge of one's information concerns and needs, and the ability to identify, locate, evaluate, organize and effectively create, use and communicate information. Science teachers should have information literacy which is a basic capability to carry out their everyday teaching lives. Science teachers should be sensitive to information resources in daily life, reinforce technology skills and integrate information technology with their instruction, and learn how to make use of WWW resources in their classroom. Constructivism theory can help teachers better integrate information technology with science education and promote instructional quality of teaching.
\end{abstract}

Keywords: Science teacher, Information literacy, Science education

\section{Introduction}

Science teachers' role in the current wave of science education reform is challenging, especially in the information society. In the information society, information literacy has become a necessity for everyone; it forms the basis for lifelong learning (Abdelaziz, 2004). Everyone needs to use information literacy to make choices that arise every day. Over the past decade, information literacy has been an area of increasing interest to science teachers.

Information literacy encompasses knowledge of one's information concerns and needs, and the ability to identify, locate, evaluate, organize and effectively create, use and communicate information to address issues or problems at hand; it is a prerequisite for participating effectively in the Information Society, and is part of the basic human right of life long learning (The Prague Declaration, 2003) . Information literacy is no longer just a library issue nowadays. It is of keen importance to all teachers and students in campus. So it will be useful for a student to be able to transfer their information literacy capability to their private life. There will also be people who have fallen through the net of formal education. Some of them may not have benefited from science education in school, but might particularly benefit from information literacy if they were information literate. An information literacy foundation could be involved in developing a strategy for information literacy as keystone for the information society and knowledge economy.

Evidences suggest that teachers are not necessarily confident users of information themselves and tend to restrict their information resources to relatively few sources (Williams and McConnell, 1997). In the case of information literacy the mediator should be a teacher. But most of science teachers use more traditional teaching methods and teaching strategies in their classroom. Science teachers must shoulder the responsibility for the cultivation of students' ability to obtain and filter information rapidly, to discriminate kinds of information accurately, and to work on and process information creatively. As the educator (facilitator and guide), science teachers should improve their information literacy which influences their professional teaching and life-long learning.

\section{Information literacy of science teachers}

The focus of the Chinese science education is the canonical knowledge of science facts, concepts, and theories. The focus on canonical knowledge is also demonstrated by the fact-driven curriculum and teacher-centered pedagogies that dominate the Chinese classrooms. In Chinese science education, the teaching content is traditional structure with less adaptation for education purposes. It has fallen behind the new development of science and information society. Science in contemporary schools should play a key role in the general education of students all of whom as citizens will have to deal with a complex technological change.

Taking into account the background of Chinese basic education reform, and on the basis of Information Literacy Competency Standards for Higher Education (ALA, 2000), we think that an information literate science teacher is able to:

- Have sensitive conscious of information resources.

- $\quad$ Determine the extent of information which is needed in science education. 
- $\quad$ Access the needed information effectively and efficiently.

- Evaluate information and its sources critically.

- $\quad$ Absorb selected information into one's knowledge instructure.

- Use information effectively, ethically and legally to accomplish instruction purpose.

\section{Cultivation of science teachers' information literacy}

In order to accomplish teaching goals and develop professional literacy, science teachers should manage to cultivate their own information literacy by some effective methods.

\subsection{Have sensitive conscious of information resources}

In the traditional Chinese science education, science teachers implement teaching that mainly rely on the textbooks and teaching syllabus, and this tradition leads to the information being used in science teaching is limited in a narrow area. Wang and Sun (2005) reported that 8 percent of the physics teachers implement teaching only depend on the textbooks, and in all $62 \%$ of them implement teaching on the basis of instruction syllabus and exam syllabus. Science teachers often have no interest to obtain other information resources to expand and enrich their teaching. Today, in the contemporary world, with the development of science and technology, students have more chances exposure to massive information which consists of much useful and useless information. Facing the information, students always can't identify, locate, evaluate, organize and effectively use and communicate information, they feel at a loss what they should do in the information society. Science teachers are responsible for guiding students conquer this problem. Students are to be willing and compliant recipients of the teachers' guiding.

Information-literate science teachers should have sensitive conscious of information resources in daily life, and broaden perspective of science education. Teachers should realize that textbooks aren't the only way to obtain information. Besides taking the information from textbooks into teaching practice, science teachers can obtain information from other resources, such as books, newspapers, periodicals, radio, TV, internet, even other educators. Teachers should have a comprehensive knowledge of their field, be able to adjust that knowledge to the circumstances of teaching, and be thoroughly prepared and organized for science teaching. They should focus on the collections and arrangements of information which involve development and frontier of science, history of science, social problems, teaching theories and student's fashions.

\subsection{Reinforce information technology skills}

Information literacy is related to information technology skill (Mustafa Koç, 2005). In China, the majority of teachers do not feel well prepared to integrate technology into their teaching. They usually think that information technology is computer operation, and always use computers as presentation tools providing additional resources in the classroom. Most of the teachers use technology to process word and make PPT course ware, they rare use technology to simulate experiment and explore software (ZHong, 2003). A study demonstrated that only 13 percent of the physics teachers usually apply technology in their classroom, $30 \%$ of them never use technology in their classroom, in all $25 \%$ of them use technology in their public class or seminar class, but it has been used as a showing tool to some extent (Wang and Sun, 2005).

Science teachers will always find a way to benefit from any new technology. Technology greatly expands science teachers' chances access to information, and changes the learning environment from a scarcity of information resources to an abundance of information resources. Science teachers should reinforce technology skills and integrate information technology with their instruction, and push forward the informational development of science education. Information technology can be used not only as an information management tool, but also as a means of teaching students of diverse information in their classroom, and promote students' problem-solving and higher-order thinking abilities.

Information technology skills enable science teachers to operator computers, software (such as PowerPoint, Excel, Flash, Authorware) applications, databases, and achieve a wide variety of information for science education. Science teachers should have capacities of obtaining information by means of information technology. Use of technology can help teachers relate to today's students who are very media aware, prompt new approaches to curriculum, and encourage developments in teaching skills (Schwarz, 2000). It can also assist teachers in helping students make connections with a worldwide community. Science teachers should understand more than how to find information; they should understand its limitations and the need to think over and examine how they chose and use information, and how to manage and communicate information in the classroom.

\subsection{Learning how to best use Word Wide Web in science education}

\subsubsection{Instructional strategies of using Word Wide Web}

The Word Wide Web (WWW) is a significant resource of science education materials (lessons, activities, projects, references, tools, etc.). Science teachers should have a positive attitude and motivate to use the WWW. Teachers with 
high motivation will find creative ways to use the WWW during lessons and be more adapt to try different approaches if one fails. Science teachers should learn how to make use of WWW resources in their classroom. Science teachers ought to learn how to use information retrieval systems (such as Google, Baidu, CNKI, et al.) access and collect the needed information for science teaching.

The instructional strategies may be designed using the WWW in any of the following ways (Relan A, 1997):

- As a resource for the identification, evaluation, and integration of a variety of information.

- As a medium of collaboration, conversation, discussions, and communication of ideas.

- As an international platform for the expression and contribution of cognitive understandings and meanings.

- As a medium for participating in simulated experiences apprenticeships, and cognitive partnerships.

3.3.2 The WWW ought to be used as a distance education tool

The WWW also can be used successfully as a distance education tool when the teachers and students have access and are comfortable with technology. Therefore, teachers can take advantage of the web resources and construct a web-based science education platform which breaks the limitation of time and space. The web-based science education platform is composed of electronic textbook, lecture materials, multi-media components, asynchronous communication tools (such as email, bulletin boards and chat rooms). From the viewpoint of science teachers, once the instruction resource is in electronic format, it's easy to organize the lecture material, modify instruction materials, communicate with the students, keep track of grades, and obtain feedback of students. The web-based science education obviously is a useful complement to in-class interactive engagement techniques. Assessing the progress of students on the Internet is similar to the conventional classroom. Homework is posted on the web and must be returned electronically to the teacher by email. Web-based assessment can be done quickly.

The web-based science education extend the boundaries of learning, help the classroom changing from a teacher-centered to a learner-centered environment in which students are active participants in the learning process. On the other hand, science teachers can communicate quickly with other teachers and experts through Internet, and obtain more information about science education.

Sciences teachers should note that information is also available outside the WWW. Information is generally concerned with families, communities, workshops, conferences, and media. These facilitated resources tend to have good values and are easily accessible.

\subsection{Implementing science teaching on the base of constructivism theory}

Science teachers must develop the knowledge and skills to integrate information technology into the existing classroom, curriculum and environment so that they become proficient in using information resources. In general, the integration between information technology and science instruction can be guided by constructivism theory, and help teachers accomplish teaching goals. The constructivist perspective is becoming a dominant paradigm in the field of the science education. Constructivism has provided the theoretical base for the science teaching approaches. Constructivist-informed teaching approaches to the process of learning are viewed as activities that explicitly aim to help students to make the constructions that lead to a conceptual understanding of the scientific points of view. As students actively make sense of the world by constructing and reconstructing their own viable meanings, constructivist-informed teaching approaches then become a matter of creating situations in which students actively participate in activities that enable them to make their own viable explanations of their sensory experiences (Peter, 2005).

Learning science is something that students do, not something that is done to them. Learning science is a process, in which students learn such skills as observing, interpreting, and experimenting (Danuse, 2007). When students learn science curriculum, they attempt to make sense of whatever phenomenon, sensory experiences or knowledge they encounter, and a consequence of this sense making process is the establishment of structures in the mind, which constitute the meaning and understanding of their own science world. Students actively develop their understanding of science by combining scientific information with reasoning and thinking skills. Therefore, on the base of abundant information, science teachers create experiences in which students will faced that will lead to appropriate processing and knowledge acquisition. Science teachers ought to reflect their own experiences of extracting information from social, and guide their students' learning effectively.

As we know, experiment and practice is the basis of science and science education. Science teachers often demonstrate scientific phenomena and experiments which can encourage students to think and make predictions about what they see in their lives. Science experiments often have been demonstrated by two forms. One is actual experiment which can be done in the laboratory and another is simulative experiment which is often simulated by computer. Computer simulation can play an important role in creating virtual experiments and inquiry. Simulations give students the opportunity to observe a real world experience and interact with it. Problem based simulations allow students to monitor experiments, 
test new models and improve their intuitive understanding of complex phenomena (Sami, 2006).

\section{Conclusion}

Information literacy is highly important not only for science teachers' teaching and lifelong learning but also fundamental for their own subject disciplines. Information literacy enables teachers to master content and extend their investigations, become more self-directed, and assume greater control over their own teaching and learning. We emphasized that information literacy is more than the ability to use technology; instead, it is the ability to find, evaluate, analyze, integrate, communicate, and use information to teaching science curriculum. Information-literate science teachers should have sensitive conscious of information resources in daily life, reinforce technology skills and integrate information technology with their instruction, and construct a web-based science education platform.

Constructivism has provided the theoretical base for science education. Constructivism theory can help teachers better integrate information technology with science education and promote instructional quality of science education.

Cultivating information literacy is the effective method to promoting science teachers' professional development, and it is the responsibility of the university and education administration to help science teachers to become information literate.

\section{References}

Abdelaziz Abid. (2004). Information literacy for lifelong learning. Retrieved July 2, 2008 from: http://www.ifla.org/IV/ifla70/papers/116e-Abid.pdf.

ALA. (2000). Information Literacy Competency Standards for Higher Education. Retrieved July 29, 2008 from: http://www.ala.org/ala/mgrps/divs/acrl/standards/standards.pdf.

Danuse Nezvalova. (2007). The Constructivist Perspective and Teaching Integrated Science: Making Science Accessible to all Students. The International Journal of Learning, 14(6),133-140.

Mustafa Koç. (2005). Implications of Learning Theories for Effective Technology Integration and Pre-service Teacher Training: A Critical Literature Review. Journal of Turkish Science Education, 2(1).

Peter HUBBER. (2005). Explorations of Year 10 students' conceptual change during instruction. Asia-Pacific Forum on Science Learning and Teaching, 6(1).

Relan A, Gillani B. J. (1997). Web-based instruction and the traditional classroom: Similarities and differences. In Khan, B. (Ed.). New Jersey: Educational Technology Publications, 25-37

Sami SAHIN. (2006). Computer simulation in science education: implications for distance education. Turkish Online Journal of Distance Education, 7 (4 ), 132-145.

Schwarz, G. (2000). Renewing teaching through media literacy. Phi Delta Kappan, 37, 8-12.

The Prague Declaration: Towards an Information Literate Society (2003). UNISIST Newsletter, $31(2), 18$.

Williams, D., McConnell, M. and Wilson, K. (1997). Is there any knowledge out there? The impact of research information on practitioners. Boston Spa: British Library. British Library Research and Innovation Report RIC/G/321.

Yuping Wang, Haibin Sun. (2005). The investigation and analysis of the knowledge structure of middle school physics teachers under new reform of course. Physics Teacher, 26(2),1-3.

Zhixian ZHong, Youmei Wang. (2003). Information Literacy of Teachers in Elementary and Secondary School. e-Education Research, 1,65-69. 